\title{
Application of Landsat Data for Urban Growth Monitoring in Jeddah
}

\author{
Mansour Almazroui ${ }^{1} \cdot$ Abdulwahab Mashat $^{1} \cdot$ Mazen Ebraheem Assiri ${ }^{1} \cdot$ Mohsin Jamil Butt $^{1}$
}

Received: 15 October 2017 / Accepted: 21 November 2017 / Published online: 30 November 2017

(c) The Author(s) 2017. This article is an open access publication

\begin{abstract}
Purpose Urbanization may be the most measured form of permanent land transformation. Jeddah, the second largest city of Saudi Arabia, has witnessed an unprecedented rate of growth over the last 40 years. In cities like Jeddah, the rapid increase in population along with the consequent urban development may have impact on the environment.

Methods Data from various sensors on the Landsat satellite have been used to monitor urban expansion in Jeddah for 41 years. For this study, eight images, three each from the Multispectral Sensor and Thematic Mapper as well as two from the Enhanced Thematic Mapper Plus between the years 1973 and 2014, were acquired and analyzed to monitor the spatial and temporal changes in Jeddah. Information on land use with regard to vegetation, bare soil, sand, urban area, rocks, road/ concrete structures, and water bodies was extracted.

Results The results of our analysis show that urbanization in the study area increased by $109.76 \mathrm{~km}^{2}$ for the period $1973-$ 2014, and in some areas has altered the structure and spatial pattern of the city. However, analyses of the impact of urban growth on temperature variations show that urban sprawl has a minimal impact on land surface temperature in the city.

Conclusions This study indicates that the most efficient way to determine the environmental impacts of urban sprawl is through the use of satellite data.
\end{abstract}

Keywords Saudi Arabia $\cdot$ Jeddah $\cdot$ MSS $\cdot$ TM $\cdot$ ETM $+\cdot$ LULC

\section{Introduction}

Urban areas are commonly defined as concentrations of people engaged in non-agricultural activities. Urban growth is a consequence of economic and social interactions affecting the land use and land cover (LULC) of a region (McIntyre et al. 2000). Over the last few decades, urbanization has been occurring at an exceptionally rapid rate thereby with distinct impact on the ecosystem. The impact of urbanization on both regional and global scales cannot be ignored (Herold et al. 2003; Liu and Lathrop 2002), as it is the main cause of reduction in the natural vegetation cover, of habitat destruction (Alphan 2003) as well as the most predominant reason for arable land loss (Lopez et al. 2001). In the recent years, researchers have been trying to understand the different effects of human activities during urbanization on

Mohsin Jamil Butt

mbutt@kau.edu.sa

1 Department of Meteorology/Center of Excellence for Climate Change Research, King Abdulaziz University, Jeddah, Saudi Arabia general environmental conditions (Stow and Chen 2002). Thus, the focus of this work is the urban growth development of a city in Saudi Arabia. Considering the escalation in urbanization, World Bank (2007) estimated that developing countries might have the largest number of megacities in the world by the end of current decade. Similarly, the UN (2008) estimated that by the end of 2050, the population of these megacities will have almost doubled. It is, therefore, important to study the urban growth development of the city.

Compared with traditional surveying methods, satellite remote sensing is considered to be an efficient although costly way of illustrating the relationship between the environment around the urban area and its population (Gatrell and Jensen 2008). Several studies (for example, Gatrell and Jensen 2008; Zeilhofer and Topanotti 2008) have established the importance of satellite data in the monitoring of urban conurbation growth (Hardin et al. 2007; Yuan 2008) as well as in the evaluation of changes in land cover in a particular region (Lopez et al. 2001; Xiao et al. 2006; Yuan et al. 2005). In particular, satellite-based multi-temporal data can provide detailed and reliable statistics on the changes in regional land cover. The results can then be used to 
develop viable environmental and urban development policies (Alphan 2003). Various techniques have been established and used to evaluate land use and changes in land cover with the help of satellite data (Coppin et al. 2004; $\mathrm{Lu}$ et al. 2004). For example, Toll et al. (1980) highlighted the use of image differencing, while Nelson (1983) used the band rationing technique. Similarly, Johnson and Kasischke (1998) studied change vector analysis, while $\mathrm{Li}$ and Yeh (1998), used a direct multi-date classification technique. Townshend and Justice (1995) highlighted the normalized difference vegetation index and Fung and LeDrew (1987) emphasized the principal component analysis technique. However, although these techniques are useful for identifying changes in the classes of land cover, they have certain disadvantages including difficulties in detecting the type of change that has occurred in a region (Ridd and Liu 1998) and therefore leads to various errors in the precision of the resultant maps highlighting the changes in the area (Yuan et al. 2005). Despite their limitations, these methods provide useful insights into the magnitude, nature and location of urban development from the generated maps (Jensen 2004).

In the recent decades, the city of Jeddah has undergone rapid growth in urban population. The population of Jeddah has increased from 0.381 million in 1971 to around 2.8 million in 2003 (3.431 million in 2010) (Census Report 2015). The transformation of rural areas into developed areas, which are consequently converted into cities with roads and infrastructure, has taken place at a remarkable speed. However, relatively little attention has been paid to the environmental issues of the city that may be among the factors in pervasive environmental problems (frequent flooding events, growing slums, mismanagement of resources, utilization of available land areas) across the city. Recently, Almazroui et al. (2013) tried to understand the impact of urbanization on the rise of air temperature over Saudi Arabia using surface observations and reported that the population rise of the country had very less impact on the temperature rise. Remote sensing and geographic information system are costeffective important tools used for monitoring LULC (Herold et al. 2003; Serra et al. 2008). For example, multi-temporal and multi-sensor satellite data are a valuable resource used for detecting the pattern of LULC change, while geographic information system technique can be used to map and analyze LULC changes. In developing countries, several factors (for example, restricted access to data, unavailability of experts in the relevant organizations) are responsible for the absence of data on land use and land cover and very little information is available regarding temporal and spatial changes in and around cities and Jeddah is not an exception. However, to predict future changes in the urban areas of a region, it is important to establish a knowledge base of the rate, pattern, and type of land use and the land cover changes of the area. Thus, it is possible, with multi-temporal and multi-sensor satellite data, to investigate the changes in land use and land cover as well as the geographical and environmental issues arising from rapid urban development (Serra et al. 2008). This empirical study, therefore, uses the satellite remote sensing technique to highlight the spatial and temporal pattern/changes in Jeddah. The main objective of the study is to use multi-temporal and multi-sensor satellite data to detect the characteristics of land use and of land cover changes as well as to illustrate the fundamental dynamic forces (generated by urban roughness or by urban heat islands) associated with these changes in Jeddah. It is expected that the results of the study will prove useful for both the scientific community and the decision-makers to assess the various dynamics affecting land use and land cover changes in the urban environment.

In the past few years, many studies have been conducted to map all or portions of Jeddah (Aljoufiea et al. 2013a, b). In this study, we estimate the LULC classification of Jeddah. This study aims to detect as well as to assess changes for Jeddah city. These assessments can deliver useful information to the city planners and decision-makers in the country. For this, data from Landsat satellite equipped with Multispectral Sensor (MSS), Thematic Mapper (TM), and Enhanced Thematic Mapper Plus (ETM+) sensors from 1973 to 2014 are used. As the total number of satellite images increase, the signatures of the various features on Earth and the accuracy of the results is expected to become more reliable with the use of geographic information for the region. It is expected that the results of the study will be valuable for the future urban development of Jeddah as well as for the growth of other residential areas in the Kingdom of Saudi Arabia.

\section{Study Area}

Jeddah territory lies at $21.71^{\circ} \mathrm{N}$ latitude, $39.18^{\circ} \mathrm{E}$ longitude (Almazroui et al. 2012a, b). Figure 1 shows the location of the Jeddah city. The general climate of the city is arid under Koppen's climate classification with summer temperatures often rising above $43{ }^{\circ} \mathrm{C}$. The mean temperature is $28.69{ }^{\circ} \mathrm{C}$ averaged over the period 1981-2010 (Almazroui et al. 2013). The city receives approximately $52.2 \mathrm{~mm}$ of rainfall annually (Almazroui et al. 2012a, b). Although some prominent incidents of thunderstorms, as well as hail have been reported during the winter season, the city remains warm in the afternoon. In addition, rainfall is infrequent and usually sparse and occurs during November and December in the city. Jeddah came into being around 3000 years ago when fishermen started to settle in it; the city then transformed into a port welcoming pilgrims arriving by sea in $647 \mathrm{AD}$. The major development of the city started between 1948 and 1956 when it became KSA's principal port. According to the Census Report (2015), the population of Jeddah in 
Fig. 1 The geographical location of the study area (Jeddah). The location of Jeddah, the second largest city in the Kingdom of Saudi Arabia
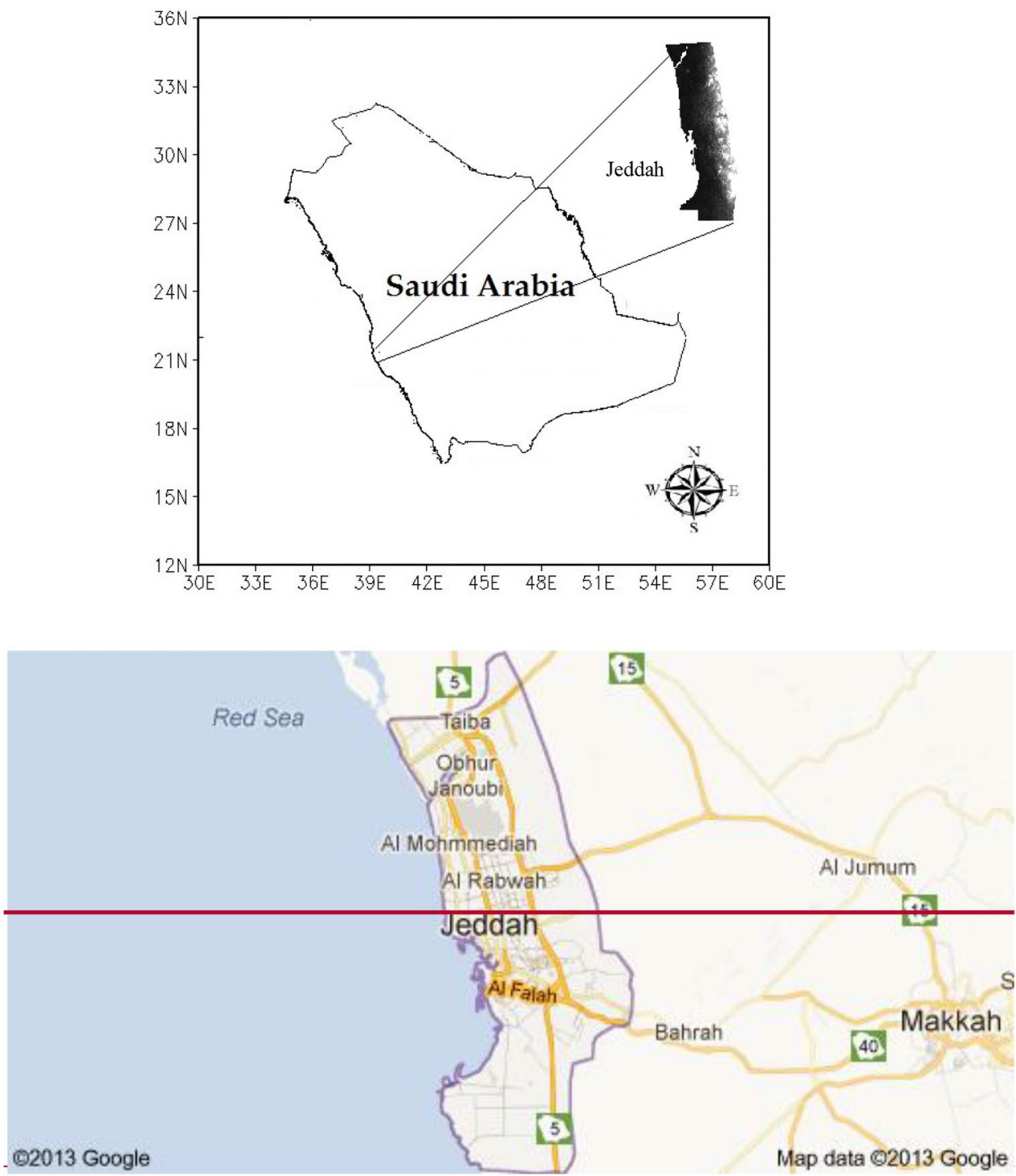

2010 was approximately 3.431 million with a growth rate of $3.5 \%$ per annum. The city of Jeddah has thus experienced several foreseen as well as unforeseen changes due to the growth in population which pose many social challenges. In addition, the population growth has triggered many factors including urban sprawl, increased demand for electricity, vehicles, etc., inside the city, with an escalation in pollution of the environment.

\section{Data Acquisition}

Landsat is the Earth Observatory System (EOS) satellite series that has been providing data since the 1970s. Landsat satellites are considered a valuable source of observation and monitoring of global changes because of the medium spatial resolution and the availability of long-term data (Masek et al. 2008; Wulder et al. 2008). For decades, data from Landsat have been widely used by scientists, researchers and policymakers to improve the understanding of various valuable Earth resources and for the purpose of planning and decision-making.

Earth resources observation and science (EROS) Center of USGS (United States Geological Survey) archives the Landsat satellite data which holds more than 40 years of records of different Landsat series data (Woodcock et al. 2008). Most of the Landsat satellite data is available free of charge to users via the internet. Landsat satellite data can be acquired via FTP (File Transfer Protocol) system from the USGS or from the GLOVIS (USGS Global Visualization Viewer) website (http://glovis.usgs.gov/). The images are geo-referenced using the UTM coordinate systems and zones 37,38 and 39 .

The remote sensing satellite which produces the images pertinent to our area of interest was launched in early 1973. Table 1 shows the relevant data from the years 1973 to 
Table 1 Characteristic of Landsat satellite sensors and its corresponding data for the study period (1973-2014)

\begin{tabular}{|c|c|c|c|c|c|c|c|c|c|c|c|c|}
\hline \multirow{2}{*}{\multicolumn{4}{|c|}{$\frac{\text { MSS data }}{1973,1975,1979}$}} & \multirow{2}{*}{\multicolumn{3}{|c|}{$\frac{\text { TM data }}{1984,1987,1998}$}} & \multicolumn{6}{|c|}{ ETM+ data } \\
\hline & & & & & & & \multicolumn{6}{|c|}{2003,2014} \\
\hline \multirow[t]{2}{*}{ Band no. } & \multicolumn{3}{|c|}{ Spectral resolution $(\mu \mathrm{m})$} & \multicolumn{3}{|c|}{$\begin{array}{l}\text { Spatial resolution } \\
\text { (meters) }\end{array}$} & \multicolumn{3}{|c|}{$\begin{array}{l}\text { Temporal resolu- } \\
\text { tion (days) }\end{array}$} & \multicolumn{3}{|c|}{$\begin{array}{l}\text { Radiometric reso- } \\
\text { lution (bits) }\end{array}$} \\
\hline & MSS & $\mathrm{TM}$ & ETM+ & MSS & $\mathrm{TM}$ & ETM+ & MSS & $\mathrm{TM}$ & ETM+ & MSS & $\mathrm{TM}$ & ETM+ \\
\hline 1 & NA & $0.45-0.52$ & $0.45-0.52$ & NA & 30 & 30 & 18 & 16 & 16 & 6 & 8 & 8 \\
\hline 2 & NA & $0.52-0.6$ & $0.53-0.61$ & & & & & & & & & \\
\hline 3 & NA & $0.63-0.69$ & $0.63-0.69$ & & & & & & & & & \\
\hline 4 & $0.5-0.6$ & $0.76-0.9$ & $0.75-0.9$ & 60 & & & & & & & & \\
\hline 5 & $0.6-0.7$ & $1.55-1.75$ & $1.55-1.75$ & & & & & & & & & \\
\hline 6 & $0.7-0.8$ & $10.4-12.5$ & $10.4-12.5$ & & 60 & 60 & & & & & & \\
\hline 7 & $0.8-1.1$ & $2.08-2.35$ & $2.1-2.35$ & & 30 & 30 & & & & & & \\
\hline 8 & NA & NA & $0.52-0.9$ & NA & NA & 15 & & & & & & \\
\hline
\end{tabular}

2014 that have been collected from the USGS via FTP. We selected three images taken by the MSS sensor (1973, 1975, and 1979) and by the TM sensor (1984, 1987, and 1998) and two ETM+ images for the years 2003 and 2014. The different spectral, spatial, temporal and radiometric characteristics of MSS, TM and ETM+ are shown in Table 1. The eight images were used to identify urban growth development as well as land use and land cover classification in Jeddah City.

In this work, we have also used census data to analyze the social impact of different land classifications. Baumont et al. (2004) have analyzed urban population distribution with a focus on the varying functions and population densities of the sprawl. The General Authority of Meteorology and Environmental Protection (GAMEP) is responsible for producing and storing meteorological and environmental data for the Kingdom of Saudi Arabia. In this study, the surface temperature data of Jeddah city (single station) for the years 1978-2014 was obtained from GAMEP and was manually inspected by the Grubbs method using statistical software, where missing values are identified and removed from the data series. It was noted that the dataset did not contain any irregular data patterns and that no inhomogeneity existed in these Jeddah station datasets. Thus, after completing all of the quality control procedures, the temperature data was then used for analysis in the current study.

\section{Methodology}

In this study, we used Principal Component Analysis (PCA) and Normalized Difference Vegetation Index (NDVI) to appraise detailed training sites, while unsupervised classification and supervised classification procedures were used to produce satellite-derived land use and land cover maps of Jeddah. The Landsat data, as shown in Table 1, have been investigated using ERDAS Imagine software. The visual interpretation of defined band combinations, PCA and NDVI, was used to identify various signatures in the satellite images, while unsupervised and supervised classifications were applied for LULC mapping. The classification technique is used to label all pixels into multiple features identified on the land surface based on training sites predefined in the image data. In the end, various thematic maps were generated using ArcGIS version 9.1 software.

\subsection{Principal Component Analysis (PCA)}

The PCA technique, a statistical method under the broad title of factor analysis (Jolliffe 2005) has been successfully used to interpret multi-spectral satellite images. In this technique, raw remote sensing data is converted into a new, more interpretable principal component image. The main aim in the use of PCA is to reduce the dimensionality of the data set. Since in satellite data a correlation exists between the bands of multi-spectral images, the PCA method helps to reduce repetitions, redundancies, and dimensionality in different bands of the satellite images. In addition, in the digital image-processing of satellite data, the PCA method is a special transformation technique to reduce the number of correlated bands in the image data to a few uncorrelated bands (Jensen 2004). Thus, the subsequent constituent images contain information on each band of the remote sensor. This method is very useful to detect major axes of inconsistency in the datasets and can be more interpretable than many multi-spectral bands. Figure 2 shows the probabilities of various land cover features in Jeddah after the application of PCA.

\subsection{Normalized Difference Vegetation Index (NDVI)}

NDVI is a numerical indicator that uses the data in the visible and near-infrared bands of the electromagnetic spectrum 

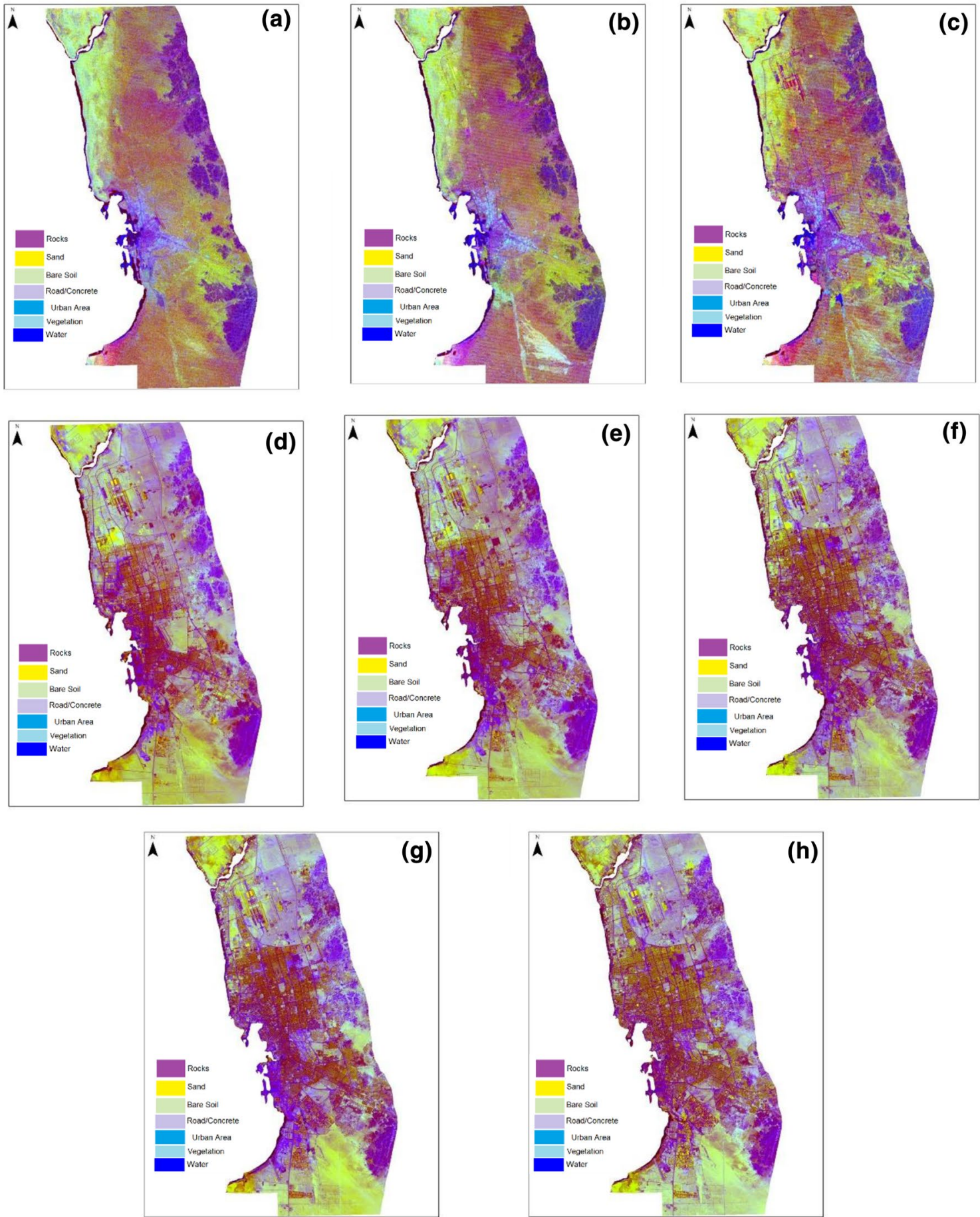

Fig. 2 PCA of Jeddah city in red-green-blue format for study period a 1973, b 1975, c 1979, d 1984, e 1987, f 1998, g 2003, and h 2014

of a sensor (Jensen 2004). NDVI is based on the red and the near-infrared part of the spectrum (red reflectancenear-infrared/red reflectance + near-infrared) The red band absorbs a considerable amount of incoming sunlight due to the presence of chlorophyll in vegetation, whilst the mesophyll structure of a plant leaf reflects sunlight in the nearinfrared band. The range of NDVI values is between -1 and
1. Higher (greater than zero) NDVI values indicate a healthy and vigorous vegetated area, while lower (less than zero) NDVI values mean either little or unhealthy vegetation. NDVI images are useful for analyzing the spatial vegetation pattern and for assessing vegetation dynamics over a large scale (Lei and Bian 2010). The measurement of NDVI is a good indicator of the strength of photosynthetically active 
vegetation and has been widely used in different studies to estimate the vegetation biomass, greenness, primary production, identification of dominant crop species, leaf area index (LAI), patterns of productivity ,etc., of an area (Wang et al. 2003). In the current study, the NDVI technique was applied to various satellite images to track vegetation coverage in the regions around Jeddah for the study period.

\subsection{Image Classification}

Various methods of classifying satellite images (for example, supervised classification, unsupervised classification and knowledge-based expert system) can be applied to remote sensing data (Stefanov and Christensen 2001; Sugumaran et al. 2003; Mundia and Aniya 2005) to extract information on land use and land cover for a region.

\subsubsection{Supervised Classification}

To evaluate the changes in land cover features, it is essential to establish a baseline dataset. Supervised classification is a image-processing technique commonly used to detect changes in land surface features in different multi-spectral global datasets (Jat et al. 2008). In supervised classification, image-processing software is trained to recognize the pixels which have similar spectral properties. It is more controlled by the user than unsupervised classification. There are two types of classes, that is, the information or signature class which is based on human activities and the spectral class which is inherited in the remote sensing data and is identified by labeling the signature. These signatures are verified using statistical analysis (standard deviation and histogram plots) and the corrected signatures of the same class are merged. Supervised classification works by classifying the pixels representing a specific feature or pattern which is identified by the user or with the help of some other sources (for example, radiometric measurements, historical data) and which is delineated on the map. For example, if the user knows that there is a lake in the study area, then the user will identify it by enclosing it on the map with a polygon or with multiple polygons (in the case of more than one lake) to generate spectral signatures. Similarly, different spectral signatures are created to include different features depending on the user's requirements. The process continues until enough features are encompassed to represent a class, and all classes in the data are identified. The grouping of similar features is considered as a class, and the polygon that covers that class is a training sample. Finally, the required algorithm for supervised classification is applied to establish the relationships within and between the classes which are stored as a signature file. Various supervised classification techniques have been developed in the literature, for example, maximum likelihood, fuzzy-rule based techniques, Bayesian, nearest neighbor, minimum distance, and parallelepiped, etc., for the classification of remotely sensed data for different applications. The selection of a suitable algorithm is very important in LULC change detection (Jensen 2004). However, the accuracy of the supervised classification is dependent on the quality of the input data, accurate identification of the features and on the algorithm used during classification (Perumal and Bhaskaran 2010; Xiaoling et al. 2007).

Landsat images have commonly been incorporated in the mapping and monitoring of natural resources and have been used effectively to classify urban areas (Xiaoling et al. 2007). For example, Yuan et al. (1998) developed the classification system for land use and land cover in USA. They defined nine different classes and concluded that the precision of the resultant map depended essentially on how accurately each feature was defined in the classification process. In this study, we categorized surfaces into seven classes (vegetation cover, bare soil, urban area, rocks, sand, road/ concrete structures and water) with the suitable combination of information from different bands and their spectral reflections from various urban features. In addition, the available reference data (assuming the most accurate and reliable data) were used to validate the classified images. More than 400 randomly selected pixels were selected from reference maps to assess the classification accuracy. In addition, the original satellite data along with some important features (key buildings, public parks, water bodies and vegetation) were also retrieved from ground visits and were used to assess the accuracy of the data as well as to avoid errors in the dataset. In this study, the overall classification accuracy is over $90 \%$, which is very encouraging. The spatiotemporal changes in the aforementioned features for the study period (1973-2014) are shown in Fig. 3.

\subsubsection{Unsupervised Classification}

Unsupervised image classification is an image-processing technique, which is used to extract information from a multiband raster image (Xu et al. 2013). The resulting raster from unsupervised classification can be used to create thematic maps for various applications. To extract information about different features from satellite data, various unsupervised classification methods (for example, K-mean and the ISODATA clustering algorithm) have been commonly used in the literature (Kanungo et al. 2002). In both algorithms (K-mean and the ISODATA clustering), an initial cluster vector is arbitrarily assigned followed by the classification of each pixel to the closest cluster. In the final step, based on all the pixels in one cluster, new cluster mean vectors are calculated. It must be noted that the above mentioned second and third steps in both K-mean and ISODATA clustering methods are repeated, until the change in the final iteration is minor. However, in the ISODATA clustering technique, 

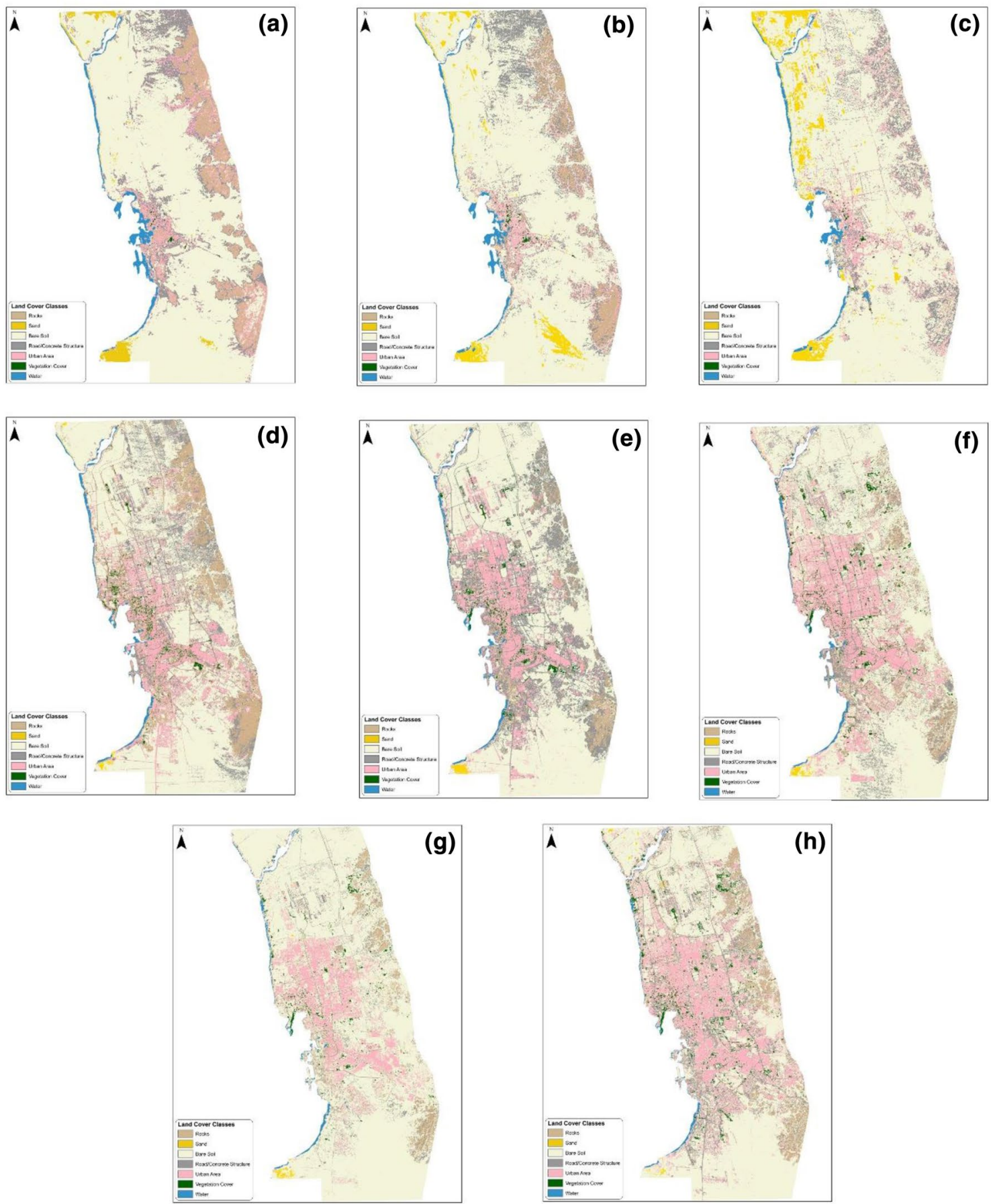

Fig. 3 The classified maps of Jeddah for the study period a 1973 b 1975 c 1979 d 1984 e 1987 f 1998 g 2003 h 2014

further refinements are made by splitting and merging clusters. Unsupervised classification works so that each class or cluster is statistically independent of the others which are based on the values of each band. Within the clusters or classes, each cluster is statistically independent of the other clusters based on the pixel values of each cell for each band (Xu et al. 2013). The information establishing the definition of the clusters is stored in a signature file which can be edited by the users for further analysis. Unsupervised classification is useful, if the user wants to know which feature is present where. Unsupervised classification automatically aggregates each of the locations into a specified number of groups or clusters. However, identification of the class or clusters for specific areas is dependent on the multivariate 
statistics which are in turn dependent on the input raster bands.

\section{Results and Analysis}

This research focuses primarily on areas composed of bare soil, sand, rocks, vegetation, water, road/concrete structure, and urban areas. There was a rapid increase in the population of Jeddah during the development of the urban areas. Satellite data has been acquired for the time frame of 1973-2014. This is done to identify the changes in the land use and land cover in the city. Seven different features (vegetation, bare soil, sand, urban area, rocks, road/ concrete structure, and water bodies) were analyzed in the current study. It is pertinent to mention here that although roads and concrete structures have a natural association with urban development and are mainly classified as urban surfaces, we have separated them into two classes, that is, urban area (mainly houses and buildings) and road/ concrete structures. This division provides us with a better understanding of the expansion of the city during the study period. For the study period (1973-2014), the changes in study features are shown in Fig. $3 \mathrm{a}-\mathrm{h}$, while the total area covered by these features is given in Table 2 .

Analyzing Fig. 3a-h, it is evident that the vegetation and urban classes have continuously increased between 1973 and 2014 in Jeddah. This increase can also be seen in Table 2, which shows that between 1972 and 2014, the area of vegetation increased from $1.29 \mathrm{~km}^{2}$, to $25.05 \mathrm{~km}^{2}$ while the area of urban construction increased from 92.75 to $202.51 \mathrm{~km}^{2}$ in Jeddah. These results show that over the study period, while the overall percentage increase in urban area $(118 \%)$ is huge, the increase in vegetation area is enormous (1842\%). The percentage increase in vegetation from 1973 to 1975 is $91 \%$, from 1975 to 1979 is $8.5 \%$, from 1979 to 1984 is $510 \%$, from 1984 to 1987 is $16 \%$, from 1987 to 1998 is $20 \%$, from 1998 to 2003 is $6.5 \%$, and from 2003 to 2014 is $1.2 \%$. However, the increase in vegetation cover from 1973 to 2014 is mainly due to certain administrative plans that were formed and implemented especially after the early 1980s, when there was a huge jump in the vegetation cover in the city. Similarly, the percentage increase in urban area from 1973 to 1975 is $6 \%$, from 1975 to 1979 is $5.4 \%$, from 1979 to 1984 is $32 \%$, from 1984 to 1987 is $15.8 \%$, from 1987 to 1998 is $12.5 \%$, from 1998 to 2003 is $5.1 \%$, and from 2003 to 2014 is $8 \%$.

Analysis of Fig. 3a-h indicates that the road/concrete structure class has an increasing/decreasing pattern in the city during the study period. This pattern is also evident from the results shown in Table 2, which reflects an increase in road/concrete structure area from the year 1973 to 1987 followed by a decreasing trend until 2014. However, the overall area of the road/concrete structure class in Jeddah city has increased from $94.16 \mathrm{~km}^{2}$ in 1973 to $120.45 \mathrm{~km}^{2}$ in 2014. The percentage increase in road/concrete structure class from 1973 to 1975 is $20.3 \%$, from 1975 to 1979 is $1.6 \%$, from 1979 to 1984 is $12 \%$, and from 1984 to 1987 is $7.8 \%$, while the percentage decrease in road/concrete structure from 1987 to 1998 is $3.3 \%$, from 1998 to 2003 is $3.1 \%$, and from 2003 to 2014 is $7.6 \%$. This increasing/decreasing pattern in the road/concrete structure class indicates that in the beginning, (from 1973 to 1987) huge concrete structures were features of the city, which were ultimately changed into urban areas during the later years of the study period.

Similarly, analyzing Fig. $3 \mathrm{a}-\mathrm{h}$, it is evident that the areas of bare soil, water bodies, rocks, and sand have continuously decreased between 1973 and 2014 in Jeddah. This decrease is also evident from the results given in Table 2, which shows that from 1972 to 2014 , the area of bare soil decreased from 634.75 to $495.99 \mathrm{~km}^{2}$, the area of water surface decreased from 23.70 to $7.83 \mathrm{~km}^{2}$, the area of rocks decreased from 78.86 to $57.70 \mathrm{~km}^{2}$, and the area of sand decreased from 16.71 to $6.03 \mathrm{~km}^{2}$. Furthermore, the overall percentage of decrease over the study period of bare soil class is $21.86 \%$, of water bodies is $67 \%$, of rocks is $26.8 \%$, and of sand surface is $63.9 \%$. The percentage decrease in bare soil from 1973 to 1975 is $3.2 \%$, from 1975 to 1979 is $0.9 \%$, from 1979 to 1984 is $8 \%$, from 1984 to 1987 is $6.5 \%$, from 1987 to 1998 is $3.4 \%$, from 1998 to 2003 is $0.7 \%$, and from 2003 to 2014 is $1 \%$. The percentage decrease in water body from 1973 to 1975 is $9.6 \%$, from 1975 to 1979 is $8 \%$,

Table 2 The total area covered by seven features in the city of Jeddah and mapped in this study between the years 1973 and 2014

\begin{tabular}{lcccrrrrr}
\hline Land cover features & $1973\left(\mathrm{~km}^{2}\right)$ & $1975\left(\mathrm{~km}^{2}\right)$ & $1979\left(\mathrm{~km}^{2}\right)$ & $1984\left(\mathrm{~km}^{2}\right)$ & $1987\left(\mathrm{~km}^{2}\right)$ & $1998\left(\mathrm{~km}^{2}\right)$ & $2003\left(\mathrm{~km}^{2}\right)$ & $2014\left(\mathrm{~km}^{2}\right)$ \\
\hline Vegetation & 1.29 & 2.47 & 2.68 & 16.34 & 19.03 & 22.93 & 24.42 & 24.73 \\
Urban area & 92.75 & 98.34 & 103.65 & 136.84 & 158.49 & 178.30 & 187.46 & 202.51 \\
Bare soil & 634.75 & 614.32 & 608.58 & 559.34 & 522.73 & 504.72 & 501.03 & 495.99 \\
Water & 23.70 & 21.42 & 19.69 & 11.58 & 10.72 & 8.95 & 8.42 & 7.83 \\
Rocks & 78.86 & 78.19 & 77.23 & 75.73 & 72.99 & 62.76 & 60.59 & 57.70 \\
Road/concrete structure & 94.16 & 113.34 & 115.22 & 129.15 & 139.25 & 134.59 & 130.36 & 120.45 \\
Sand & 16.71 & 15.10 & 14.21 & 10.84 & 9.71 & 7.23 & 6.64 \\
\hline
\end{tabular}


from 1979 to 1984 is $41.1 \%$, from 1984 to 1987 is $7.4 \%$, from 1987 to 1998 is $16.5 \%$, from 1998 to 2003 is $5.9 \%$, and from 2003 to 2014 is $7 \%$. The percentage decrease in rocks from 1973 to 1975 is $0.8 \%$, from 1975 to 1979 is $1.2 \%$, from 1979 to 1984 is $1.9 \%$, from 1984 to 1987 is $3.6 \%$, from 1987 to 1998 is $14 \%$, from 1998 to 2003 is $3.4 \%$, and from 2003 to 2014 is $4.7 \%$. The percentage decrease in sand from 1973 to 1975 is $9.6 \%$, from 1975 to 1979 is $5.8 \%$, from 1979 to 1984 is $23.7 \%$, from 1984 to 1987 is $10.4 \%$, from 1987 to 1998 is $25.5 \%$, from 1998 to 2003 is $8.1 \%$, and from 2003 to 2014 is $9.1 \%$. These results clearly indicate that due to the rapid development in the urban area, the areas of bare soil, water body, rocks, and sand in Jeddah have been decreasing over the study period.

The increase in urban development over the years has had a certain impact on the city environment. For example, the absorption of solar radiation by the urban class is much higher due to higher thermal capacity and conductivity, which consequently has higher temperatures compared with rural areas (containing large areas of vegetation). In the current study, we have also analyzed the influence of urban development on temperatures in the city. For this, the daily temperature data of Jeddah city (single station) for the years 1978 to 2014 obtained from GAMEP is converted into mean annual temperature for the study period and is shown in Fig. 4. It is evident from Fig. 4 that the city has large variations in the mean average annual temperature with the minimum temperature $\left(26.87^{\circ} \mathrm{C}\right)$ being observed for the year 1992 . The average annual mean temperature for the city has risen from $28.19^{\circ} \mathrm{C}$ in 1978 to $29.4{ }^{\circ} \mathrm{C}$ in 2014 (also the highest average annual temperature of the city during study period). However, considering the large variation in the average annual mean temperature, this increase in temperature may not be due to urban development alone.

Another important indicator of urban development is land surface temperature (LST). In the process of urban

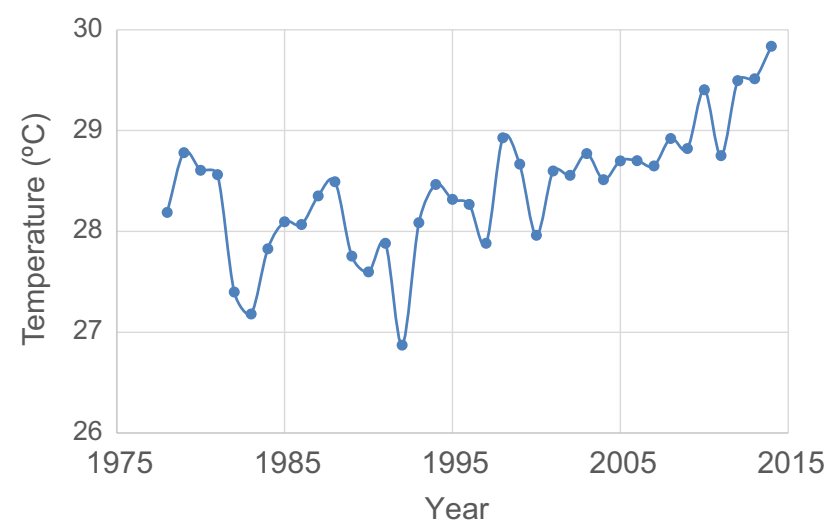

Fig. 4 Mean annual temperature of Jeddah between the years 1978 and 2014
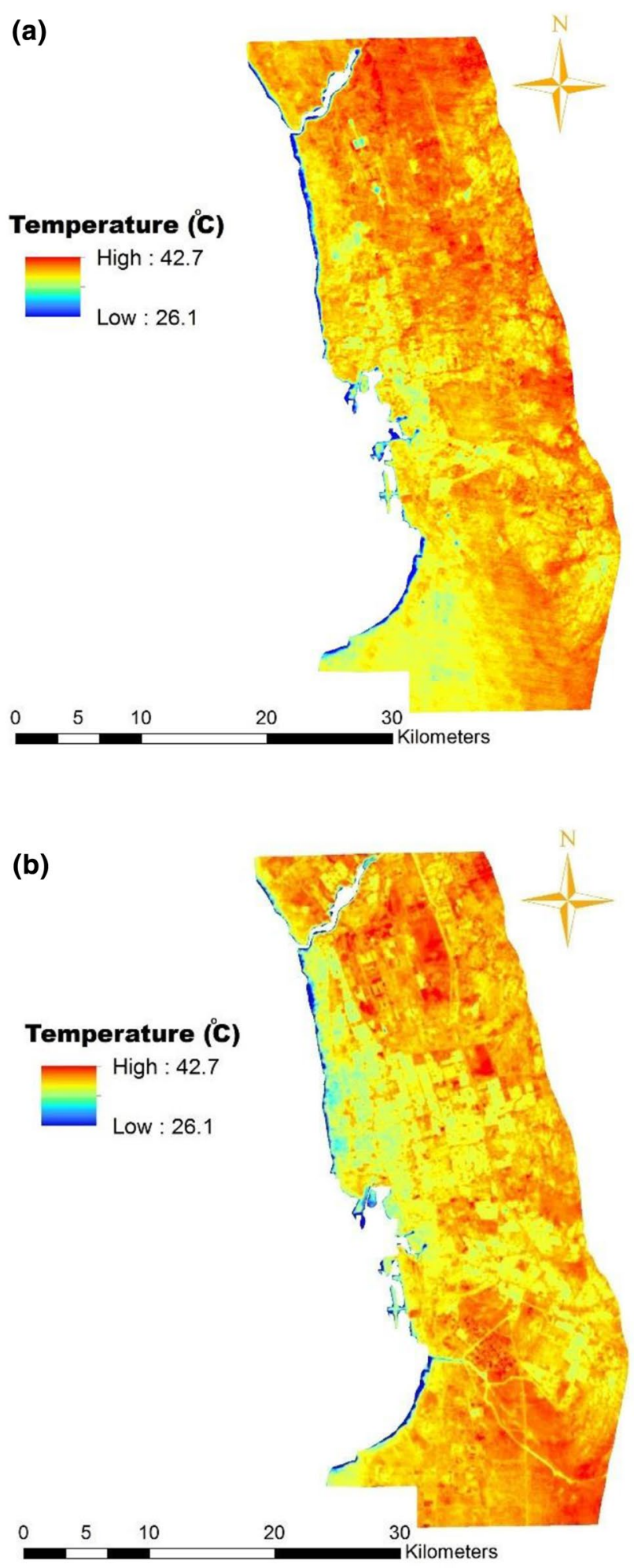

Fig. 5 LST maps of Jeddah using Landsat thermal band data for the years a 1984 and b 2014 
development, massive constructions of commercial, residential and industrial infrastructures can lead to an increase in LST in a region. LST maps, the brightness temperature of the land surface can be prepared using satellite thermal band data. Thus, Landsat thermal band data from 1984 to 2014 is used to demonstrate the LST of Jeddah and are shown in Fig. 5a, b. Although widespread urban development has been observed in Jeddah (Table 2), the 1984 LST map (Fig. 5a) demonstrates higher LST values for a large portion of the city than the 2014 map (Fig. 5b). One important reason that should be considered in analysis of this factor is that before urban development took place, significant parts of Jeddah consisted of bare soil which has relatively high reflectivity in the thermal region of electromagnetic radiation compared to urban constructions. Nevertheless, it is evident from Fig. 5a, $b$ that the range of LST values has widened following the development of urban areas in the city.

\section{Conclusions}

The objective of the current study is to analyze multi-temporal and multi-sensor Landsat satellite data to identify and map surface features of the environs of the city of Jeddah. All the analysis in this research has been conducted using available satellite images. For this, Landsat MSS, TM, and ETM+ data for the study period (1973-2014) were acquired and analyzed using PCA, NDVI, supervised and unsupervised classification methods. In addition, census data as well as GAMEP data were integrated with satellite images using GIS technique. One of many advantages of the GIS is that the statistical results can be displayed spatially on the map. Thus, a combination of GIS technology and remote sensing is considered to be a valuable and powerful tool in the study of urban conurbation growth.

The results of the current study clearly indicate that the reduction in bare soil, water area, rocks, and sand areas are linked to the development of the urban area as well as with an increase in vegetation over the study period in Jeddah. In addition, the highest percentage of reductions in these features is observed between 1979 and 1998, which is also the period with the highest rate of increase in urban development and vegetation in the city. For example, it is evident from Fig. 3a-h that the areas of bare soil, rocks, and sand visible in the 1973 image have been converted to either an urban area or vegetation cover in the subsequent years. Similarly, in the early years of Landsat images, the coastal water area, which later on was converted into urban area, has been demarcated as water body in the current study. Thus, the overall decrease $(67 \%)$ in water surface is associated with the urban development of the city. There are, however, some errors related to satellite remote sensing data, which can cause observations to fluctuate greatly. For example, changes and inconsistencies in the observed images resulted from different satellite related resolutions (spatial, radiometric, spectral, and temporal) of a particular sensor and from meteorological conditions in the study area at the time the data was recorded by the satellite. These variations in urbanization, as seen on the sensor of the satellite, cannot be explained merely by remote sensing images.

It is widely accepted that modern and technologically advanced countries have a superior database publically available for research applications. It is therefore critical to improve the current monitoring capabilities of various urban areas as well as to channel the existing resources in the Kingdom of Saudi Arabia. It is highly recommended that such studies should be conducted frequently to update the statistical and census data as well as to produce higher spatial maps of the area.

Open Access This article is distributed under the terms of the Creative Commons Attribution 4.0 International License (http://creativecommons.org/licenses/by/4.0/), which permits unrestricted use, distribution, and reproduction in any medium, provided you give appropriate credit to the original author(s) and the source, provide a link to the Creative Commons license, and indicate if changes were made.

\section{References}

Aljoufiea M, Zuidgeest M, Brussel M, Maarseveen M (2013a) Spatialtemporal analysis of urban growth and transportation in Jeddah City, Saudi Arabia. Cities 31:57-68

Aljoufiea M, Brussel M, Zuidgeest M, Maarseveen M (2013b) Urban growth and transport infrastructure interaction in Jeddah between 1980 and 2007. Int J Appl Earth Obs Geoinform 21:493-505

Almazroui M, Islam MN, Athar H, Jones PD, Rahman MA (2012a) Recent climate change in the Arabian Peninsula: annual rainfall and temperature analysis of Saudi Arabia for 1978-2009. Int J Climatol 32:953-966

Almazroui M, Islam MN, Jones PD, Athar H, Rahman MA (2012b) Recent climate change in the Arabian Peninsula: seasonal rainfall and temperature climatology of Saudi Arabia for 1979-2009. Atmos Res 111:29-45

Almazroui M, Islam MN, Jones PD (2013) Urbanization effects on the air temperature rise in Saudi Arabia. Clim Change 120:109-122

Alphan H (2003) Land use change and urbanization in Adana, Turkey. Land Degr Dev 14(6):575-586

Baumont C, Ertur C, Le Gallo J (2004) Spatial analysis of employment and population density: the case of the agglomeration of Dijon 1999. Geogr Anal 36(2):146-176

Coppin P, Jonckheere I, Nackaerts K, Muys B, Lambin E (2004) Digital change detection methods in ecosystem monitoring: a review. Int J Rem Sen 25(9):1565-1596

Fung T, LeDrew E (1987) The application of principal component analysis to change detection. Photogramm Eng Rem Sen 53:1649-1658

Gatrell JD, Jensen RR (2008) Sociospatial applications of remote sensing in urban environments. Geogr Compass 2(3):728-743

Hardin PJ, Jackson MW, Otterstrom SM (2007) Mapping, measuring, and modeling urban growth. In: Jensen RR, Gatrell JD, McLean D (eds) Geo-spatial technologies in urban environments: policy, 
practice and pixels, 2nd edn. Springer-Verlag, Heidelberg, pp 141-176

Herold M, Goldstein NC, Clarke KC (2003) The spatiotemporal form of urban growth: measurement, analysis and modeling. Rem Sen Environ 86:286-302

Jat MK, Grag PK, Khare D (2008) Monitoring and modeling of urban sprawl using remote sensing and GIS techniques. Int J Appl Earth Obs Geoinform 10:26-43

Jensen JR (2004) Digital change detection. Introductory digital image processing: a remote sensing perspective. New Jersey: PrenticeHall, pp 467-494

Johnson RD, Kasischke ES (1998) Change vector analysis: a technique for the multi-temporal monitoring of land cover and condition. Int J Remote Sen 19(3):411-426

Jolliffe I (2005) Principal component analysis. Encyclopedia of statistics in behavioral science, vol 3. John Wiley \& Sons. Ltd., Chichester, pp 1580-1584

Kanungo T, David M, Nathan SN, Christine DP, Ruth S, Angela Y (2002) An efficient k-means clustering algorithm: analysis and implementation. In: IEEE transactions on pattern analysis and machine intelligence. Vol. 24, No. 7

Lei S, Bian Z (2010) Analysis of spatiotemporal difference of NDVI in an arid coal Mining region using remote sensing. ISPRS TC VII symposium-100 Years ISPRS, Vienna, Austria, July 5-7, 2010, IAPRS, Vol. X

Li X, Yeh AGO (1998) Principal component analysis of stacked multitemporal images for the monitoring of rapid urban expansion in the Pearl River Delta. Int J Remote Sens 19:1501-1518

Liu X, Jr Lathrop RG (2002) Urban change detection based on an artificial neural network. Int J Remote Sens 23:2513-2518

Lopez E, Bocco G, Mendoza M, Duhau E (2001) Predicting land cover and land use change in the urban fringe a case in Morelia City, Mexico. Landsc Urb Plan 55(4):271-285

Lu D, Mausel P, Brondiozio E, Moran E (2004) Change detection techniques. Int J Remote Sens 25(12):2365-2407

Masek JG, Vermote HC, Wolfe R, Cohen W, Hall F, Kutler J, Nelson P (2008) North American forest disturbance mapped from a decadal Landsat record. Remote Sens Environ 112:2914-2926

Mcintyre NE, Knowles-Yanez K, Hope D (2000) Urban ecology as an interdisciplinary field: differences in the use of "urban" between the social and natural sciences. Urb Ecosys 4:5-24

Mundia CN, Aniya M (2005) Analysis of land use/cover changes and urban expansion of Nairobi city using remote sensing and GIS. Int J Remote Sens 26:2831-2849

Nelson RF (1983) Detecting forest canopy changes due to insect activity using Landsat MSS. Photogramm Eng Remote Sens 49:1303-1314

Perumal K, Bhaskaran R (2010) Supervised classification performance of multispectral images. J Comput 2(2):124-129

Population Census Organization, Statistics Division, Kingdom of Saudi Arabia, 2015

Ridd MK, Liu J (1998) A comparison of four algorithms for change detection in an urban environment-a remote sensing perspective. Remote Sens Environ 63:95-100

Serra P, Pons X, Saur' D (2008) Land-cover and land-use change in a Mediterranean landscape: a spatial analysis of driving forces integrating biophysical and human factors. App Geogr 28:189-209

Stefanov WL, Christensen MS (2001) Monitoring urban land cover change: an expert system approach to land cover classification of semiarid to arid urban centers. Remote Sens Environ 77:173-185
Stow DA, Chen DM (2002) Sensitivity of multi-temporal NOAA AVHRR data of an urbanizing region to land use/cover changes and misregistration. Remote Sens Environ 80:297-307

Sugumaran R, Pavuluri MK, Zerr D (2003) The use of high resolution imagery for identification of urban climax forest species using traditional and rule based classification approach. IEEE Trans Geosci Remote Sens 41:1933-1939

The World Bank (2007) Dhaka: Improving living conditions for the urban poor. Sustainable Development Unit, South Asia Region, Report No. 35824-BD

Toll DL, Royal J, Davis JB (1980) Urban areas update procedures using Landsat data. In: Proceedings of American Society of Photogrammetry. Falls Church, American Society of Photogrammetry

Townshend JRG, Justice CO (1995) Spatial variability of images and the monitoring of changes in the normalized difference vegetation index. Int J Remote Sens 16:2187-2195

United Nation (2008) Report of the meeting-urbanization: a global perspective. In: Proceedings of the expert group meeting on population distribution, urbanization, internal migration and development, 21-23 January, 2008, New York

Wang J, Rich PM, Price KP (2003) Temporal responses of NDVI to precipitation and temperature in the central Great Plains, USA. Int J Remote Sens 24:2345-2364

Woodcock CE, Allen AA, Anderson M, Belward AS, Bindschadler R, Cohen WB, Gao F, Goward SN, Helder D, Helmer E, Nemani R, Oreapoulos L, Schott J, Thenkabail PS, Vermote EF, Vogelmann J, Wulder MA, Wynne R (2008) Free access to Landsat imagery. Science 320:320-1011

Wulder MA, White JC, Goward SN, Masek JG, Irons JR, Herold M, Cohen WB, Loveland TR, Woodcock CE (2008) Landsat continuity: issues and opportunities for land cover monitoring. Remote Sens Environ 112:955-969

Xiao J, Shen Y, Ge J, Tateishi R, Tang C, Liang Y, Huang Z (2006) Evaluating urban expansion and land use change in Shijiazhuang, China, by using GIS and remote sensing. Landsc Urb Plan 75:69-80

Xiaoling C, Xiaobin C, Hui L (2007) Expert classification method based on patch-based neighborhood searching algorithm. Geosp Inf Sci 10:37-43

Xu K, Yang Wen, Liu G, Sun H (2013) Unsupervised satellite image classification using markov field topic model. IEEE Geosci Remote Sens Lett 10(1):130-134

Yuan F (2008) Land-cover change and environmental impact analysis in the Greater Mankato area of Minnesota using remote sensing and GIS modelling. Int J Remote Sens 29(4):1169-1184

Yuan D, Elvidge CD, Lunetta RS (1998) Survey of multispectral methods for land cover change analysis. Remote Sensing Change Detection: Environ Mon Meth App. Michigan' Ann Arbor Press, Ann Arbor, pp 21-39

Yuan F, Sawaya KE, Loeffelholz BC, Bauer ME (2005) Land cover classification and change analysis of the Twin Cities (Minnesota) Metropolitan Area by multi-temporal Landsat remote sensing. Remote Sens Environ 98(2-3):317-328

Zeilhofer P, Topanotti VP (2008) GIS and ordination techniques for evaluation of environmental impacts in informal settlements: a case study from Cuiaba', Central Brazil. App Geogr 28:1-15 